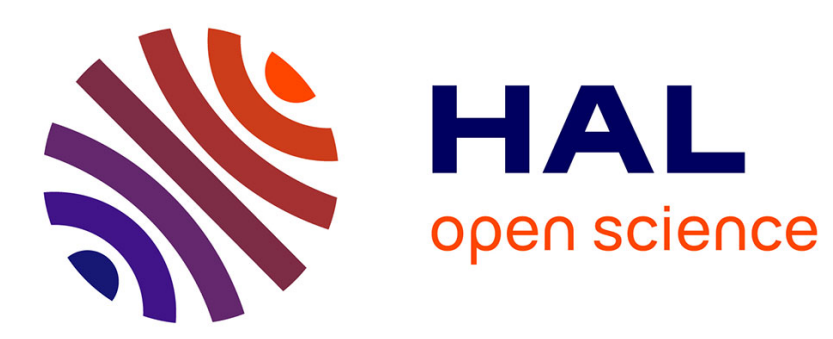

\title{
High temperature phase transformation kinetics and their effects on diffusion bonding of Ti-48Al-2Mn-2Nb
}

S. Godfrey, P. Threadgill, M. Strangwood

\section{To cite this version:}

S. Godfrey, P. Threadgill, M. Strangwood. High temperature phase transformation kinetics and their effects on diffusion bonding of Ti-48Al-2Mn-2Nb. Journal de Physique IV Proceedings, 1993, 03 (C7), pp.C7-485-C7-488. 10.1051/jp4:1993779 . jpa-00252199

\section{HAL Id: jpa-00252199 https://hal.science/jpa-00252199}

Submitted on 1 Jan 1993

HAL is a multi-disciplinary open access archive for the deposit and dissemination of scientific research documents, whether they are published or not. The documents may come from teaching and research institutions in France or abroad, or from public or private research centers.
L'archive ouverte pluridisciplinaire HAL, est destinée au dépôt et à la diffusion de documents scientifiques de niveau recherche, publiés ou non, émanant des établissements d'enseignement et de recherche français ou étrangers, des laboratoires publics ou privés. 


\title{
High temperature phase transformation kinetics and their effects on diffusion bonding of Ti-48Al-2Mn-2Nb
}

\author{
S.P. GODFREY, P.L. THREADGILL* and M. STRANGWOOD \\ IRC in Materials for High Performance Applications, School of Metallurgy and Materials, The University \\ of Birmingham, Elms Road, Edgbaston, Birmingham B15 2TT, U.K. \\ ${ }^{*}$ TWI, Abington Hall, Abington, Cambridge CB1 6AL, U.K.
}

\begin{abstract}
Diffusion bonding of the intermetallic compound Ti-48Al-2Mn-2Nb has been carried out in order to determine what effect temperature, time and starting base microstructure have on the bond line microstructure, in particular the extent of grain growth that occurs at the interface.

The results showed that the non-equilibrium lamellar and duplex microstructures gave more grain growth at the interface compared with the equilibrium fully $\gamma$ microstructure for bonding upto 45 minutes in the temperature range $1200^{\circ} \mathrm{C}-1350^{\circ} \mathrm{C}$. It was also observed that the base microstructure in the duplex and fully $\gamma$ samples was little changed during bonding, whereas in the lamellar samples decomposition of the lamellar $\left(\alpha_{2}+\gamma\right)$ regions to allotriomorphic $\gamma$ occurred, particularly at $1250^{\circ} \mathrm{C}$.
\end{abstract}

\section{Introduction}

At present, most of the published work on titanium aluminides has concentrated on the improvement of low temperature mechanical properties through alloy development and processing. Little work has been done on the joining of these alloys; some work has been published on laser beam welding of titanium intermetallics $(1,2,3)$, but little has been published on solid state diffusion bonding ${ }^{(4)}$ and the effect that the joining process will have on the base microstructure which, particularly in titanium aluminides, have been optimised for mechanical properties.

In order to achieve sound diffusion bonds in titanium aluminides it is necessary to determine what effect individual parameters such as time, temperature, pressure and microstructure have on the bonding process. In particular, the development of the bond line microstructure, which exerts a strong influence on the strength of the bond needs to be determined.

The bond line microstructure of diffusion bonds in Ti-48Al-2Mn-2Nb have been studied as a function of temperature $\left(1200^{\circ} \mathrm{C}-1350^{\circ} \mathrm{C}\right)$, time $(15,45$ minutes) and starting base microstructures (fully lamellar, duplex and fully $\gamma$ ) at a constant pressure of $10 \mathrm{MPa}$.

\section{Experimental}

Cylindrical pieces of $\gamma$ titanium aluminide with a nominal composition of Ti-48Al-2Mn-2Nb, $10 \mathrm{~mm}$ in diameter and approximately $5 \mathrm{~mm}$ high were electrodischarge machined (EDM) from an ingot made by plasma arc remelting at the IRC, University of Birmingham. The cylindrical pieces were ground on 1200 grit $\mathrm{SiC}$ paper until the bonding faces were perfectly flat and parallel; particular care was taken to ensure that the surfaces to be bonded were ground back far enough to remove any contaminated, interstitial-rich layer that may have developed during the EDM process. Interstitial 
that would promote decomposition of the $\gamma$ grains to give Widmanstätten $\alpha_{2}$. Hence, there is a limit on the temperature and cooling rate used to avoid $\alpha_{2}$ precipitation during cooling if the specimens spend a greater time in the $\alpha_{2}+\gamma$ phase field. In the fully lamellar samples it was seen, that at $1250^{\circ} \mathrm{C}$ rapid growth of twin related $\gamma$ grains from the lamellar colonies occurred. This growth was not as rapid at temperatures of $1300^{\circ} \mathrm{C}$ and $1350^{\circ} \mathrm{C}$, which is in agreement with recent high temperature dilatometery studies at Birmingham. For the lamellar samples it would be possible to bond at relatively high temperatures below the $\beta$ tranus (approximately $1395^{\circ} \mathrm{C}$ for this alloy) without too much decomposition of the lamellar colonies. The bonding mechanism appears to be one where twin related $\gamma$ grains nucleate on both sides of the original boundary and then grow into the bulk of the material with only a limited number of grains growing across the boundary. Hence, the bond consists of a relatively large area of grain boundary type interfaces and the strength of the bond will be related to the strength of these interfaces. In this case the presence of any oxides or films on the surface of the bonding surfaces is likely to be very detrimental to the bonding process and hence clean, high vacuum conditions should be used in order to minimise the formation of brittle layers such as $\mathrm{TiO}_{2}$. In some of the samples there was evidence of a 'skin' of $\alpha_{2}$, particularly at any exposed surfaces that formed as a result of interstitial oxygen pick-up during the bonding process. Any such layer will be relatively stable compared with the $\gamma$ grains and is likely to inhibit grain growth across the interface, even when grain growth does occur $\alpha_{2}$ platelets may be retained at the original boundary location as indicated in Figure 2, particularly for higher bonding temperatures and starting microstructures containing $\gamma$ allotriomorphs.

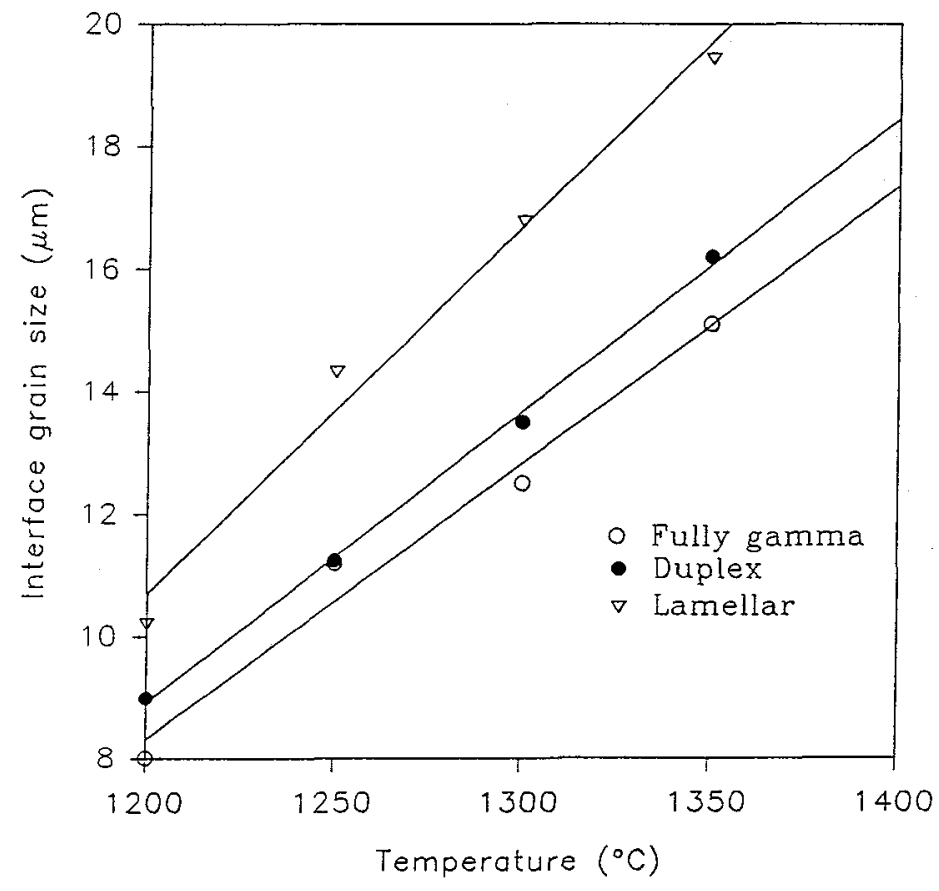

Figure 1. Variation in interfacial grain size for the 3 microstructures

\section{Conclusion}

The main microstructural effects noted for diffusion bonding Ti-48Al-2Mn-2Nb for upto 45 minutes 
contamination of the bonding surfaces may affect the bonding behaviour of the alloy. Diffusion bonding of the alloys was carried out in a high vacuum, high temperature 'Instron' 8501

servohydraulic machine at a vacuum level of $10^{-5} \mathrm{~Pa}$. The samples were separated from the load train by high purity alumina sheets. The samples were heated at $30 \mathrm{C} \mathrm{min}^{-1}$ to the bonding temperature and furnace cooled at a rate of approximately $50 \mathrm{OC} \mathrm{min}^{-1}$ once the bonding was completed. A nominal stress of $0.8 \mathrm{MPa}$ was applied to the samples during heating to the bonding temperature, once at temperature a stress of 10MPa was applied to the samples. After bonding the samples were sectioned using a low speed diamond saw and polished to a $1 / 4 \mu \mathrm{m}$ diamond finish prior to etching in a solution of $0.5 \% \mathrm{HF}$ in $\mathrm{H}_{2} \mathrm{O}$.

Examination of the bond line microstructure was carried out using optical microscopy and by scanning electron microscopy (SEM) on a Jeol 6300 equipped with a Link AN10000 EDX system.

\section{Results}

The bond line microstructures developed with respect to time, temperature and starting microstructure are shown in Figure 1 . In virtually all cases it was observed that small twin related $\gamma$ grains nucleated and grew away from the original boundary with only limited growth of grains across the original boundary.

In general, it was observed that the non-equilibrium lamellar and duplex microstructures gave relatively faster grain growth at the boundary compared with the equilibrium $\gamma$ microstructure. The fully lamellar samples bonded at the higher temperatures showed evidence of slight porosity at the bond line, presumably due to Kirkendall effects that occurred as a result of diffusion processes associated with the dissolution of $\alpha_{2}$.

In the fully $\gamma$ samples bonded at the higher temperatures there was evidence of a Widmanstätten type microstructure, which was only partially observed in the allotriomorphic $\gamma$ regions of the duplex samples and was not detected at all in the allotriomorphic $\gamma$ regions of the near lamellar samples. With respect to the base microstructure little change in the $\gamma$ grain size was observed for the full $\gamma$ samples at any of the temperatures, whereas in the duplex and lamellar samples formation of allotriomorphic $\gamma$ occurred, particularly at $1250^{\circ} \mathrm{C}$ where the transformation appeared to be rapid. The Energy Dispersive X-Ray spectroscopy (EDX) analysis did not reveal the presence of any composition changes or the formation of any interfacial layers at the boundary.

\section{Discussion of Results}

The ideal bonding condition is one that produces a sound, defect-free joint at the minimum possible time without too much loss of any beneficial properties in the base material. Nakao(4) has shown that it was possible to obtain reasonable bonds in $\mathrm{Ti}-38 \% \mathrm{Al}$ with tensile strengths around $200 \mathrm{MPa}$ by diffusion bonding at $12000^{\circ} \mathrm{C}$ under a compressive load of $15 \mathrm{MPa}$,

It is also necessary, particularly with titanium aluminides to choose bonding conditions that do not promote rapid grain growth or decomposition of desirable phases such as lamellar colonies which would lead to a decrease in mechanical properties such as fracture toughness. In the fully $\gamma$ samples rapid grain growth in the base material did not appear to occur under any of the conditions studied and hence it would be possible to bond at as high a temperature as possible without greatly affecting the base microstructure. The Widmanstätten structure seen in the high temperature fully $\gamma$ samples was $\alpha_{2}$ laths that precipitated from the $\gamma$ matrix during the relatively slow furnace cooling of the specimens in the vacuum Instron. The $\alpha_{2}$ laths were present predominately in the fully $\gamma$ sample due to the $\alpha_{2}$ stabilising elements such as $\mathrm{Mn}$ and $\mathrm{O}$ being more evenly distributed in the $\gamma$ grains, whereas in the duplex and near lamellar samples the $\alpha_{2}$ stabilising elements were concentrated in the $\alpha_{2}$ lamellae. Hence the allotriomorphic $\gamma$ grains were relatively free from the $\alpha_{2}$ stabilising elements 
in the temperature range $\left(1200^{\circ} \mathrm{C}-1350^{\circ} \mathrm{C}\right)$ are:

1. Limited grain growth across the boundary occurred.

2. The bond line microstructure consists mainly of fine $(10-20 \mu \mathrm{m})$ twin-related $\gamma$ grains.

3. Little variation in base microstructure grain size occurred for the fully $\gamma$ and duplex samples.

4. For the lamellar and duplex samples coarsening of the lamellae occurred particularly at $1250^{\circ} \mathrm{C}$.

5. High vacuum conditions should be used with strict control over the partial pressure of $\mathrm{O}_{2}$ to avoid oxygen pick-up which will stabilise the $\alpha_{2}$ phase at any free surfaces.

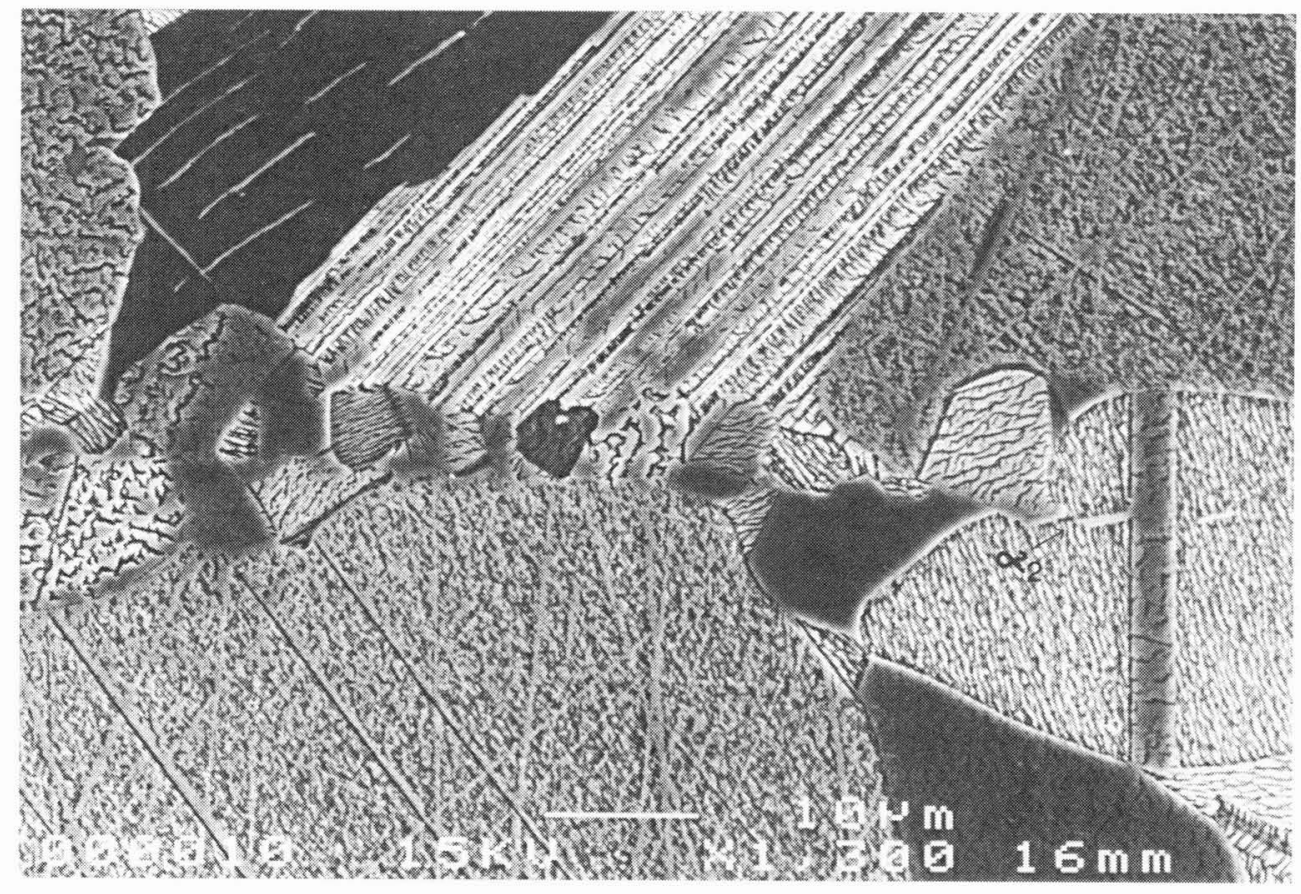

Figure 2. Scanning electron micrograph showing typical bond line microstructures

\section{References}

1. DAVID S.A., HORTON J.A., GOODWIN G.M., PHILLIPS D.H. and REED R.W., Welding Journal, 69 (4), (1990), S133-S140.

2. PATTERSON R.A., MARTIN P.L., DAMKROGER B.K. and CHRISTODOULOU L., Welding Journal, $\underline{69}$ (1), (1990), S39-S44.

3. BAESLACK W.A., CIESLAK M.J. and HEADLEY T.J., Scripta Metallurgica, 22 (7), (1988), 1155-1160

4. NAKAO Y., SHINOZAKI K., HAMANDA M., ISIJ International, $\underline{31}$ (10), (1991), 1260-1266 